\section{Percutaneous transhepatic biliary drainage}

\section{after failed endoscopic approach in patients with pancreatic cancer and situs inversus totalis}

Situs inversus totalis is a rare entity with complete transposition of all viscera, making endoscopic, radiological, and surgical procedures challenging and complicated. Endoscopic retrograde cholangiopancreatography (ERCP) is the main treatment modality in patients with extrahepatic malignant biliary obstruction $[1,2]$, but in patients with situs inversus totalis, this presents a technical challenge and often fails to achieve duct access [3]. In patients with extrahepatic malignant biliary obstruction, when ERCP fails, percutaneous transhepatic biliary drainage represents a good alternative to decompress the biliary system $[4,5]$.

We describe two patients with situs inversus totalis and common bile duct (CBD) obstruction as a result of pancreatic cancer ( $\bullet$ Fig. 1) in whom endoscopic retrograde cholangiopancreatography failed, but both were subsequently treated successfully with percutaneous transhepatic biliary drainage.

It was decided to place the patients on the angiography table in the supine position but on the opposite side (feet first) without artificially reversing the image on the monitor. The procedure was performed after local anesthesia with a left subcostal access, between the X and XII ribs on the middle axillary line, using a $21 \mathrm{G}$ Chiba needle.

The cholangiography showed a dilatation of the biliary tree with a stricture at the distal CBD ( $\bullet$ Fig. 2a). A 0.18 guidewire was inserted into the bile duct, then the coaxial system was advanced into the bile duct and the intestinal lumen was reached with a 0.035 hydrophilic guide and a 4Fr MP catheter, and an 8-Fr internal-external drainage was positioned with an Amplatz guidewire ( $\bullet$ Fig. 2 b).

Seven days after the procedure, a self-expanding metal stent (SEMS) $(10 \mathrm{~mm}$ in diameter, $68 \mathrm{~mm}$ length) was placed at the level of the obstruction ( Fig. 2 c). At the end of the procedure, an 8-Fr internal-external drainage was positioned and cholangiography performed. This showed a good patency and the correct positioning of the SEMS ( $\mathbf{F i g} . \mathbf{2} \mathbf{d}$ ).

There were no complications in either patient during the procedures and the internal-external drainage has been removed from both patients.

Endoscopy_UCTN_Code_TTT_1AR_2AJ

Competing interests: None
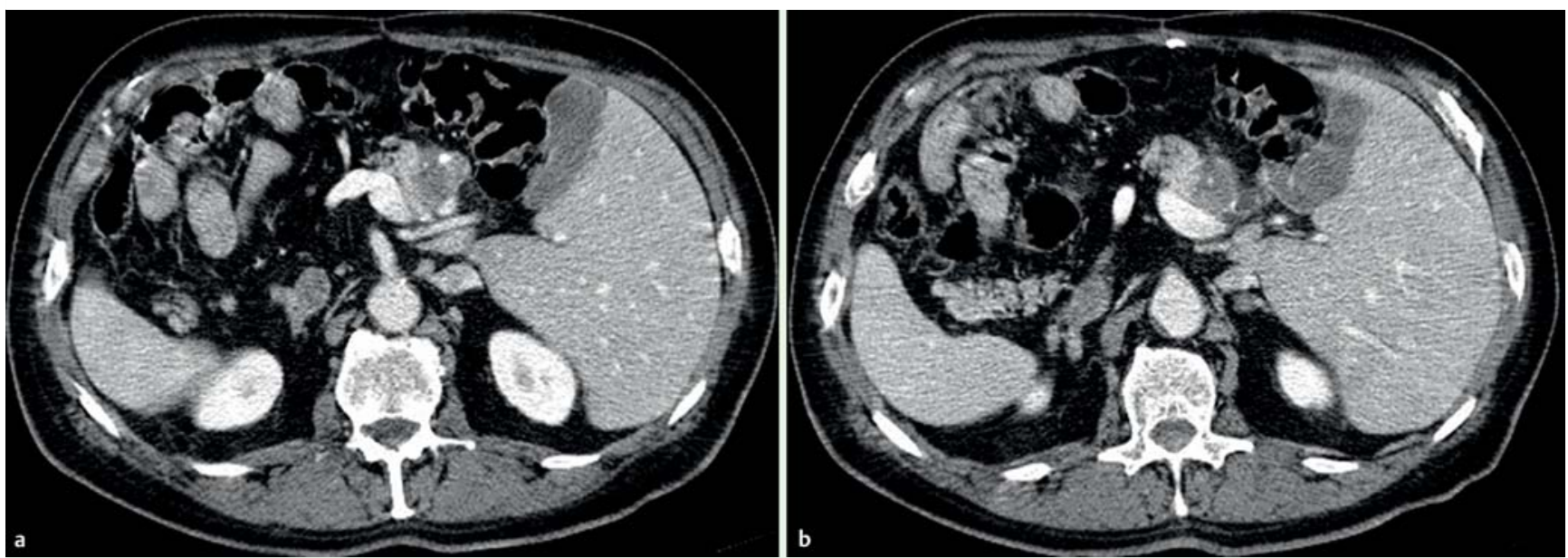

Fig. 1 a Enhanced computed tomography (CT) scan showing the mirror anatomy of situs inversus totalis in an 80-year-old woman with epigastric pain and a history of jaundice; the liver is on the left side without significant distension of the intrahepatic biliary tracts. $\mathbf{b}$ The pancreatic lesion in close contact with the portal vein and initial dilatation of the common bile duct.
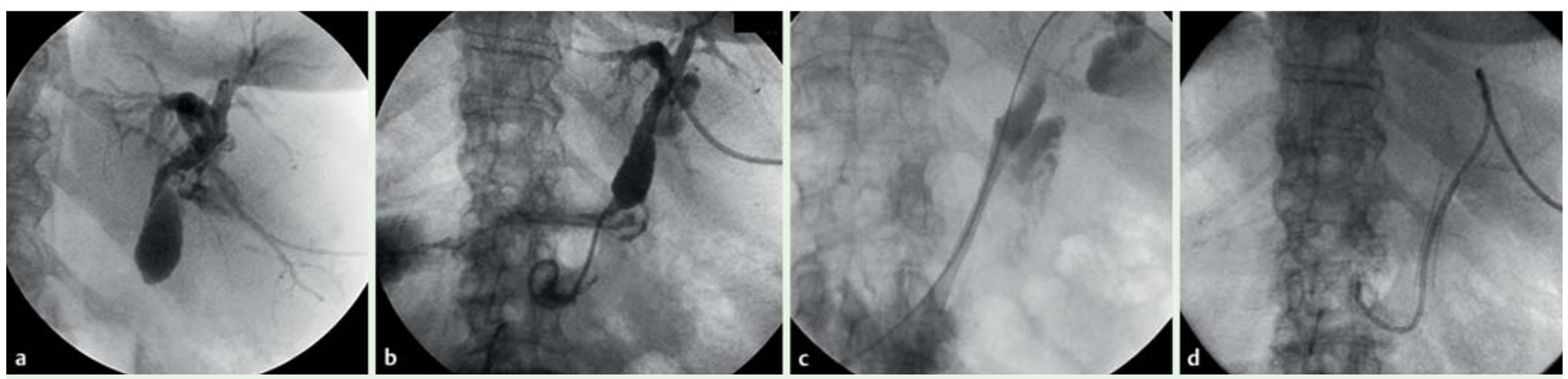

Fig. 2 A 75-year-old woman presented with anorexia, nausea, significant weight loss, epigastric pain, fever, and jaundice. a Cholangiography showed a dilatation of the biliary tree with an obstruction in the lower third of the common bile duct. $\mathbf{b}$ The 8-Fr internal-external drainage correctly positioned with the distal part in the duodenum. c An Amplatz guidewire was used to place the self-expanding metal stent at the level of the obstruction. $\mathbf{d}$ The self-expanding metal stent fully open with an 8-Fr internal-external drainage. 


\section{Giuseppe Giordano ${ }^{1}$, Stefania \\ Bonomo², Giovanni Failla², \\ Carmelo Luigiano ${ }^{3}$, Simona Caloggero ${ }^{4}$, Vincenzo Magnano San Lio ${ }^{1}$}

${ }^{1}$ Unit of Diagnostic and Interventional Radiology, ARNAS Garibaldi, Catania, Italy

2 Department of Radiology, A.O. Ospedaliero Universitaria "Policlinico - Vittorio Emanuele”, Catania, Italy

${ }^{3}$ Gastroenterology and Digestive Endoscopy, ARNAS Garibaldi, Catania, Italy

${ }^{4}$ Unit of Diagnostic and Interventional Radiology, University Hospital

“G. Martino", Messina, Italy

\section{References}

1 Çoban S, Yüksel I, Küçükazman M et al. Successful ERCP in a patient with situs inversus. Endoscopy 2014; 46 (Suppl. 01): E222

2 García-Fernández FJ, Infantes JM, Torres $Y$ et al. ERCP in complete situs inversus viscerum using a "mirror image" technique. Endoscopy 2010; 42 (Suppl. 02): E316 - 317

3 Bakman YG, Freeman ML. Difficult biliary access at ERCP. Gastrointest Endosc Clin N Am 2013; 23: 219-236

4 Saad WE, Wallace MJ, Wojak JC et al. Quality improvement guidelines for percutaneous transhepatic cholangiography, biliary drainage, and percutaneous cholecystostomy. J Vasc Interv Radiol 2010; 21: 789-795

5 Garcea G, Ong SL, Dennison AR et al. Palliation of malignant obstructive jaundice. Dig Dis Sci 2009; 54: 1184-1198
Bibliography

DOI http://dx.doi.org/

10.1055/s-0034-1390779

Endoscopy 2014; 46: E628-E629

(c) Georg Thieme Verlag KG

Stuttgart · New York

ISSN 0013-726X

\section{Corresponding author} Giuseppe Giordano, MD Unit of Radiology ARNAS Garibaldi Nesima Hospital Via Palermo 636

95122 Catania Italy

Fax: +39-095-7595173

g.giorda@gmail.com 